\title{
Walter Vogt
}

Erhard Taverna

Der Arzt und Schriftsteller Walter Vogt zweimal fotografiert von Peter Friedli.
Walter Vogt wurde am 31. Juli 1927 in Zürich geboren und starb am 21. September 1988 in Muri bei Bern. Nach einem Medizinstudium in Zürich arbeitete er als Radiologe im Tiefenauspital in Bern und führte später eine Praxis als Facharzt für Psychiatrie in Muri. Bekannt wurde er mit seinem 1966 publizierten ersten Roman «Wüthrich», einem langen inneren Monolog eines sterbenden Chefarztes während der letzten Spitalvisite. Nicht gerade das, was die Zunft begeisterte. Es muss aus jener Zeit zahlreiche Leserbriefe geben, von denen auch einige den Rausschmiss aus der Ärztegesellschaft forderten. Walter Vogt war Arzt und Patient, er experimentierte mit Drogen und schrieb Dramen, Fernsehspiele, Hörspiele, Essays und Reden. Er wurde ins Französische, Polnische und Chinesische übersetzt, verfilmt und mehrfach ausgezeichnet. 1978 war er für ein Semester «Writer in Residence» an der University of Southern California, Los Angeles. Im Kollegenkreis

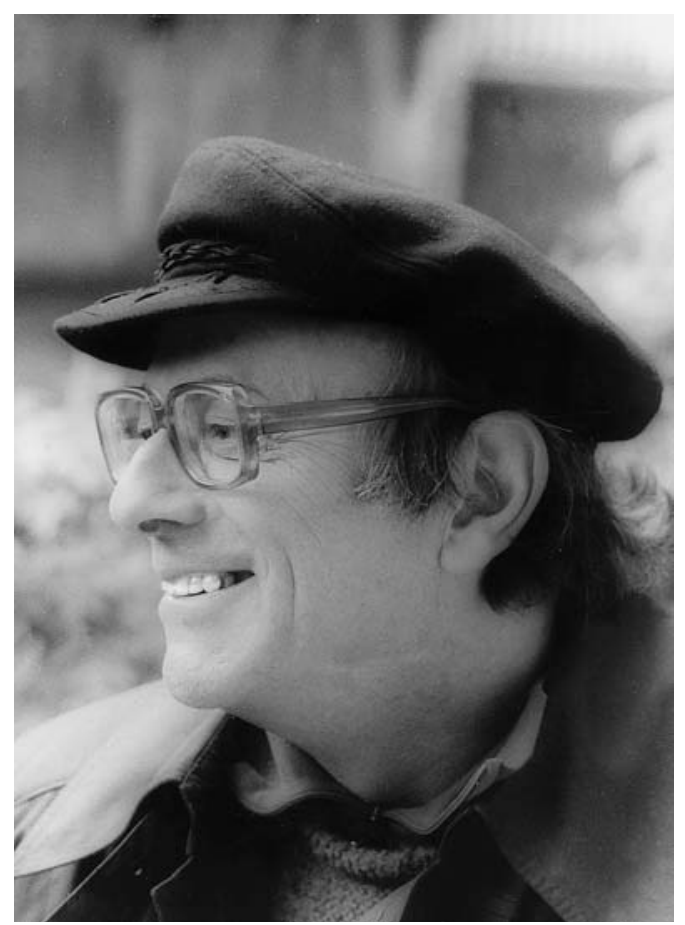

blieb er trotzdem ein ärgerlicher Fremdkörper, doch ausserhalb war er ein vielgelesener Autor, der es beim Verlag Nagel \& Kimche postum zu einer zehnbändigen Werkausgabe brachte.

Vor der Appenzeller Ärztegesellschaft spottete er einmal: «Ich glaube kaum an ernsthafte Schwierigkeiten, wenn ich hübsche Gedichte, Sonette vielleicht, von bunten Blumen, dunklen Jungfrauen und hellen Jünglingen herstellen würde. Vielleicht würde die Ärztezeitung sogar dann und wann eines davon abdrucken, als besinnliche Probe aus dem Schaffen eines Kollegen, der neben seiner aufreibenden Arbeit als Röntgenarzt noch Zeit und Musse findet, sich allem Schönen, Wahren und Guten zu öffnen. Allein: Ich tu's nicht.» Er interpretierte seinen «Wüthrich», mit dem er zu Unrecht identifiziert werde, um dann auf das Bündnis der Ärzte mit der Macht einzugehen. Damals war es noch einfach, das autoritätsgewohnte Publikum mit einem unkon-

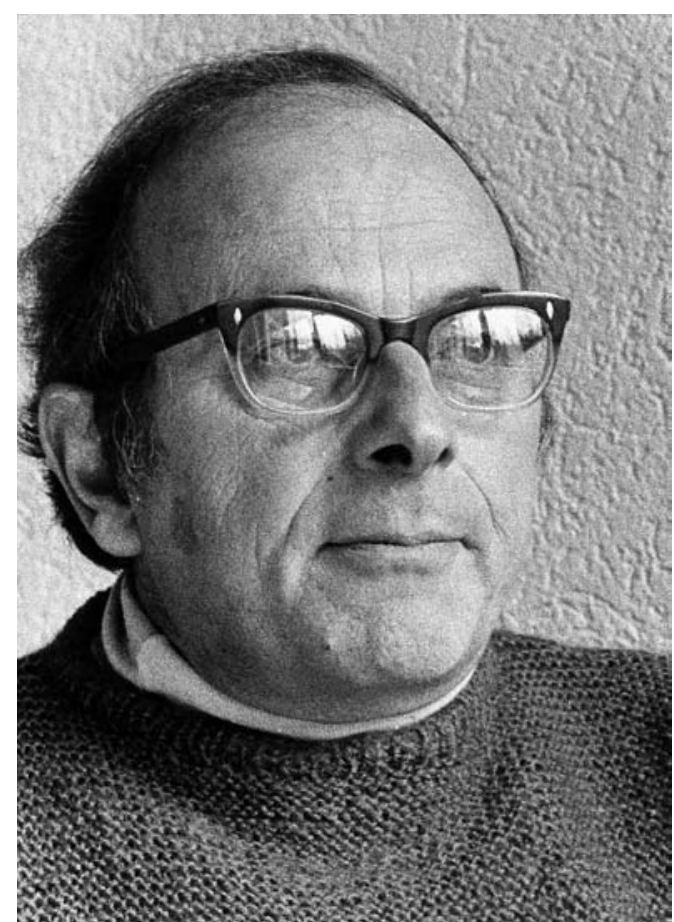


trolliert dahinsiechenden Chef zu provozieren. Und wenn er diesen sagen liess: «Steinreiche und bettelarme Menschen können noch Gutes tun. Der Mittelstand ist zu sehr mit sich selber beschäftigt», dann war auch klar, wen er diesem Mittelstand zurechnete.

Nein - Walter Vogt war nie bequem, er hat es sich und anderen oft schwergemacht. Als Assistent las ich mit Vergnügen «Der Wiesbadener Kongress», die Geschichte eines teuren und labyrinthischen Forschungsprojektes einer grossen psychiatrischen Klinik, das sich als gigantischer Leerlauf entpuppt. Eine makabre Aufführung mit karrieregeilen oder debilen Assistenten, devoten Oberärzten und einem einsamen, leicht senilen Chef: «Je kleiner die Teilchen, die erforscht werden, desto grösser die Anlagen, mit denen es geschieht. [...] Und wenn es die Teilchen gar nicht gibt? Wenn sie einzig Resultat der angewandten Forschungsmethoden wären? Auch das würde niemanden stören.» Amüsant waren auch die Erlebnisse des Amateurkriminalisten Beno von Stürler, unterhaltende Kurzgeschichten, vereinigt im Band «Melancholie». Walter Vogt hatte ein breites Repertoire, konnte hintergründig witzig, ironisch, sarkastisch, aber auch ehrlich und selbstkritisch schreiben, was er mit weiteren Romanen, darunter bekannten wie «Schizogorsk» oder «Booms Ende», immer wieder aufs neue bewies.

Heute scheint er vergessen zu sein, seine Bücher sind zum grössten Teil vergriffen, weitere Auflagen scheinen nicht geplant. Dem Neueinsteiger rate ich, sein autobiographisches Werk von 1981, «Altern», zu lesen. Der zehnte Band der Werkausgabe, «Schreiben als Krankheit und als Therapie», vereinigt Reden und Essays, die einen guten
Überblick über sein Denken erlauben. Die Fotos stammen vom Arzt und Fotografen Peter Friedli, der den Autor als Hausarzt betreute. Er hat mich an den Schriftsteller erinnert, der im Juli seinen 80. Geburtstag feiern würde. Der Literaturwissenschaftler Peter von Matt erwähnt Walter Vogt 2004 in seinem Buch «Die tintenblauen Eidgenossen» nur mit Namen, ohne auf sein Werk einzugehen. Er steht da in einer Reihe mit Hermann Burger, Fritz Zorn, Adolf Muschg, Thomas Hürlimann, Peter Noll und anderen.

Krebs- und Krankheitsbücher gab es in jener Dekade in grosser Zahl. Krankheit und Krebs als elementare Naturereignisse, als Metapher für zerstörte Landschaften, für das Versagen der Technik, für eine Zivilisation am Abgrund. Von Matt drückt das so aus: «Im Privaten zeigten sie, was öffentlich kommen sollte. In ihrer altertümlichen Art, die Welt zu erfahren, verspürten die Dichter das ganze Land wie den eigenen Körper als Teil des ganzen Landes, und so wurde ihre Rede ganz intim und furchtbar verbindlich für alle.» Walter Vogt war ein engagierter und leidender Kollege, das spricht für ihn. Vieles liest sich auch heute noch aktuell, seinen Gedankengängen zu folgen lohnt sich immer noch. Dass er als wacher Geist ein Nestbeschmutzer war, ehrt ihn auch nachträglich. Gut möglich, dass er eines Tages plötzlich wieder zum literarischen Ereignis, zur neuen Entdeckung wird. Vielleicht trifft die Bemerkung von Peter von Matt auch auf ihn zu: «In der Schweiz haben die herausragenden Künstler nach ihrem Hinschied längerfristig nur zwei Möglichkeiten: die Vergemütlichung oder das Vergessen.» Ersteres ist ihm vorläufig erspart geblieben. 